\title{
Comparative study of polypropylene composites reinforced with oil palm empty fruit bunch fiber and oil palm derived cellulose
}

\begin{abstract}
In recent years, the race for producing biodegradable products has increase tremendously. Different approaches have been attempted to use biomass as natural biopolymer for production of biodegradable plastics. In this work, cellulose was derived from oil palm empty fruit bunch fiber (EFBF) by standard ASTM D1104 method. The cellulose and EFB fibers were blended in different ratios up to 50-wt.\% with polypropylene (PP) using Brabender twin-screw compounder. Effects of cellulose and EFB fibers on the mechanical properties of PP were investigated. Studies on the morphological properties and the influence of fiber loading on the properties of PP-cellulose and PP-EFBF composites were also conducted. The PP-cellulose composite gave better results in comparison with PP-EFBF composite. The changes in mechanical and morphological properties with different cellulose and fiber loading were discussed.
\end{abstract}

Keyword: Empty fruit bunch fiber (EFBF); Polypropylene; Cellulose; Tensile strength; Scanning electron microscopy (SEM); Composite; Thermoplastic 